\title{
Sleep, Rhythms, and the Endocrine Brain: Influence of Sex and Gonadal Hormones
}

\author{
Jessica A. Mong, ${ }^{1,2}$ Fiona C. Baker, ${ }^{3,4}$ Megan M. Mahoney, ${ }^{5}$ Ketema N. Paul, ${ }^{6}$ Michael D. Schwartz, ${ }^{1}$ Kazue Semba, ${ }^{7}$ \\ and Rae Silver ${ }^{8,9}$ \\ ${ }^{1}$ Department of Pharmacology and Experimental Therapeutics and 2Program in Neuroscience, University of Maryland School of Medicine, Baltimore, \\ Maryland 21201-1559, ${ }^{3}$ Human Sleep Research Laboratory, SRI International, Menlo Park, California 94025-3493, ${ }^{4}$ Brain Function Research Group, School \\ of Physiology, University of the Witwatersrand, Johannesburg, South Africa, ${ }^{5}$ Department of Comparative Biosciences, University of Illinois, Urbana, \\ Illinois 61802, ${ }^{6}$ Department of Neurobiology, Morehouse School of Medicine, Atlanta, Georgia 30310-1495, ${ }^{7}$ Department of Anatomy and Neurobiology, \\ Dalhousie University, Halifax, Nova Scotia B3H 4R2, Canada, ${ }^{8}$ Departments of Psychology, Barnard College and Columbia University, New York, New York \\ 10027, and ${ }^{9}$ Department of Pathology and Cell Biology, Columbia University Medical Center, New York, New York 10032
}

While much is known about the mechanisms that underlie sleep and circadian rhythms, the investigation into sex differences and gonadal steroid modulation of sleep and biological rhythms is in its infancy. There is a growing recognition of sex disparities in sleep and rhythm disorders. Understanding how neuroendocrine mediators and sex differences influence sleep and biological rhythms is central to advancing our understanding of sleep-related disorders. While it is known that ovarian steroids affect circadian rhythms in rodents, the role of androgen is less understood. Surprising findings that androgens, acting via androgen receptors in the master "circadian clock" within the suprachiasmatic nucleus, modulate photic effects on activity in males point to novel mechanisms of circadian control. Work in aromatase-deficient mice suggests that some sex differences in photic responsiveness are independent of gonadal hormone effects during development. In parallel, aspects of sex differences in sleep are also reported to be independent of gonadal steroids and may involve sex chromosome complement. This a summary of recent work illustrating how sex differences and gonadal hormones influence sleep and circadian rhythms that was presented at a Mini-Symposium at the 2011 annual meeting of the Society for Neuroscience.

\section{Introduction}

Establishing sleep-wake patterns: circadian rhythms and sleep homeostasis

Living organisms, from cyanobacteria to plants and animals, have in common intrinsic biological "clocks" that determine the timing of daily biochemical, physiological, and behavioral changes, including the sleep-wake cycle. These intrinsic circadian rhythms occur over an $\sim 24 \mathrm{~h}$ cycle and can be resynchronized or entrained by external cues such as the light to dark cycle (for review, see Antle and Silver, 2005). From an adaptive standpoint, the ability to synchronize the circadian system and the processes under its timing to the external environment is critical for the organism's survival and well-being. Disruptions in the circadian system due to shift work, jet lag, and lifestyles impair cognitive

Received Aug. 11, 2011; revised Sept. 16, 2011; accepted Sept. 20, 2011.

This work was supported by National Heart, Lung, and Blood Institute (HL085037-J.A.M., HL088088 and HL103688 - F.C.B.), National Institute of Neurological Disorders and Stroke (NS37919 — R.S., NS34194 and NS060659 - K.P.), National Institute of Mental Health (MH075045-R.S.), the Science and Technology Centers program of the National Science Foundation under agreement number IBN-9876754 (K.N.P.), and Canadian Institutes of Health Research (MOP-67085-K.S.). We thank M. K. Holder and D. Cusmano for comments on the manuscript.

Correspondence should be addressed to Jessica A. Mong, Department of Pharmacology and Experimental Therapeutics, University of Maryland School of Medicine, 655 West Baltimore Street, Baltimore, MD 21212. E-mail: jmong001@umaryland.edu.

M. D. Schwartz's present address: Center for Neuroscience, Biosciences Division, SRI International, Menlo Park, CA 94025-3493.

DOI:10.1523/JNEUROSCI.4175-11.2011

Copyright $\odot 2011$ the authors $\quad 0270-6474 / 11 / 3116107-10 \$ 15.00 / 0$ function and increase the risk for metabolic and cardiovascular dysfunction (Spiegel et al., 1999; Gangwisch, 2009; Kyriacou and Hastings, 2010; Kronholm et al., 2011).

In mammals, the master circadian clock generating the body's intrinsic rhythms lies in the suprachiasmatic nucleus (SCN), a highly conserved bilateral hypothalamic nucleus lying immediately above the optic chiasm (Klein et al., 1991). Lesions of the SCN abolish circadian rhythmicity for sleep and other biological processes (Moore and Eichler, 1972; Stephan and Zucker, 1972; Eastman et al., 1984; Edgar et al., 1993; Mistlberger, 2005; Kohsaka and Bass, 2007). While the SCN signals the timing of sleep-wake cycles, an intricate neurocircuitry consisting of neurochemically distinct nuclei residing in the basal forebrain, preoptic area, lateral hypothalamus, and brainstem is responsible for the induction and maintenance of arousal and the different sleep stages, rapid eye movement sleep (REMS) and non-REMS (for review, see Jones, 2005; Saper et al., 2005; Szymusiak and McGinty, 2008; Saper et al., 2010; Siegel, 2011). The SCN and sleep-wake neurocircuits are anatomically linked (Chou et al., 2002, 2003; Deurveilher et al., 2002; Deurveilher and Semba, 2003, 2005), and neurobiological research over the past 30 years clearly points to an interaction between homeostatic and circadian processes in the regulation of sleep-wake cycles (for review, see Mistlberger, 2005; Saper et al., 2005; Franken and Dijk, 2009; Rosenwasser, 2009). However, exactly how the SCN controls the timing of sleep-wake and whether the SCN plays an active 
role in modulating sleep architecture (i.e., sleep duration, bout lengths, etc.) are active areas of investigation (for review, see Mistlberger, 2005).

Sex differences and ovarian hormone influences over sleep and circadian rhythms

Sex influences brain anatomy, chemistry, and function (Cahill, 2006). The large majority of sex differences in the nervous system are mediated by developmental exposure to gonadal hormones that permanently organize the neural substrate, setting the stage for functional differences between the sexes. These functional differences typically emerge when gonadal hormones act on the differentiated circuitry across puberty and adulthood (McCarthy and Arnold, 2011). Early evidence from animals (Malven and Sawyer, 1966; Colvin et al., 1968; Colvin et al., 1969; Branchey et al., 1971) as well as humans (Hartmann, 1966; Williams, 1971; Ballinger, 1976; Schiff et al., 1979) suggested a significant modulation of sleep-wake cycles by ovarian steroids in females and to a lesser extent by testicular steroids in male rats (Yamaoka, 1980). Although harder to detect in men, there is a relationship between testosterone levels and sleep (Evans et al., 1971; Schiff et al., 1979; Luboshitzky et al., 1999). In parallel, gonadal steroids in both male and female rodents modify the amplitude, free-running period (tau), and phase of daily rhythms (Fitzgerald and Zucker, 1976; Morin et al., 1977; Albers et al., 1981; Davis et al., 1983; Karatsoreos and Silver, 2007).

Since the time of these early observations, clinical and basic studies have further confirmed the influence of gonadal steroids and sex differences in sleep regulation and circadian timing. While much is known about the mechanisms of sleep and circadian timing, the investigation into sex differences and reproductive hormonal control of sleep is in its infancy. Here we seek to illustrate how sex differences and gonadal hormones influence sleep and circadian rhythms, providing new insights into the link between reproductive endocrine and sleep pathologies. As the sex disparities in sleep disorders become increasingly clear (for review, see Paul et al., 2008), elucidating how reproductive neuroendocrine mediators act is central to advancing our understanding of sleeprelated disorders.

\section{Clinical perspective-sleep and rhythm disorders \\ Sex differences in sleep and circadian function}

Epidemiological data are useful in identifying salient sex differences in the human population and directing mechanistic research in animal models of these phenomena. Clinical evidence indicates that men and women sleep differently. Women spend more time in bed and sleep longer, but report a poorer sleep quality than men across a wide age range (for review, see Manber et al., 2006). The perception of a poorer sleep quality in women is not reflected in objective polysomnographic (PSG) measures of sleep architecture: women have less wakefulness after sleep onset, less light Stage 1 sleep, more slow-wave sleep (i.e., non-REMS), and more slow-wave activity (SWA; delta, $\sim 0.4-4 \mathrm{~Hz}$ ) during sleep compared to men (for review, see Manber et al., 2006).

The perception of poorer sleep quality in the absence of PSG sleep disturbances in women may, in part, be driven by sleepindependent factors, such as mood (F. C. Baker, unpublished data). Sleep quality assessments are strongly influenced by anxiety, depressive symptoms, and affective disorders, which are more common in women and may contribute to a higher incidence of insomnia. Women are at a $40 \%$ greater risk for developing insomnia, and the risk ratio grows with age (Zhang and Wing, 2006). This sex difference in insomnia emerges after puberty (Fig. 1)

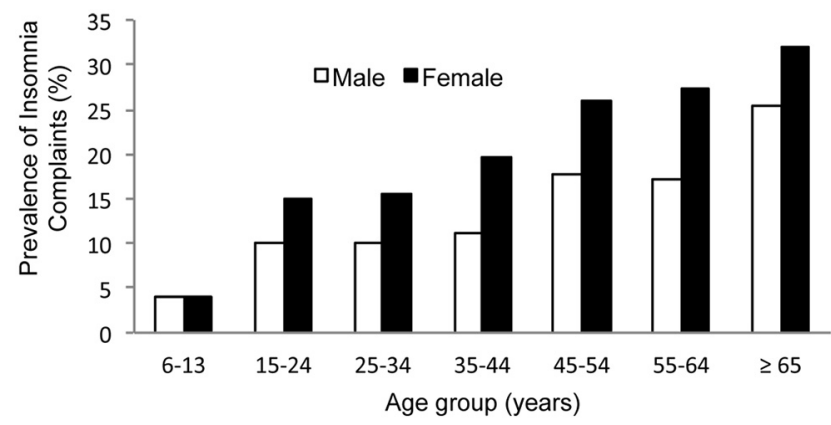

Figure 1. Prevalence of insomnia complaints by sex and age in a general population. Sleep disorders among women are a significant public health issue: sleep complaints such as insufficient sleep and insomnia are more prevalent in women. This sex difference in insomnia emerges after puberty, suggesting that hormonal events underlying puberty may be involved. Data are redrawn from Zhang et al. (2009) and Ohayon (1997).

(Johnson et al., 2006), suggesting that hormonal changes underlying puberty may be involved. Interestingly, the rate of depression also becomes sexually differentiated after puberty, becoming twice as common in girls as in boys (Born et al., 2002).

Perhaps the best evidence of sex differences in the circadian timing system is seen in age-and sex-dependent timing of sleep onset. Women go to bed earlier than men from childhood to menopause, at which time sex differences disappear (Roenneberg et al., 2007). A subsequent study reported that women have phase-advanced endogenous temperature and melatonin rhythms (Cain et al., 2010), partly as a consequence of a significantly shorter circadian period (Duffy et al., 2011). Circadian timing in women is even earlier than the sex difference in sleep timing would predict. Women, therefore, may be sleeping at a later circadian time than men, which could contribute to the higher prevalence of insomnia, particularly sleep maintenance insomnia, in women (Duffy et al., 2011). Sex differences in circadian timing may also differentially impact the ability of men and women to adapt to changing shift-work schedules and jetlag.

\section{Sex differences in homeostatic response to sleep loss}

Emerging evidence suggests that sleep debt accumulates more quickly in women and may become more debilitating, giving rise to sex differences in the ability to recover from sleep loss (Armitage et al., 2001). Women have higher levels of SWA during baseline sleep and a greater SWA rebound following sleep deprivation than men, suggestive of sex differences in slow-wave sleep regulation (Manber and Armitage, 1999; Armitage et al., 2001). Sex differences in SWA responses to sleep deprivation, sleep amount, and both objective and subjective sleep quality may arise from a differential rate in the accumulation and dissipation of sleep pressure between men and women. For women, the impact of sleep loss appears to be more detrimental to health outcomes than for men. In fact, recent studies have shown that restricting sleep puts women at a higher risk for developing hypertension, cardiovascular problems, and metabolic disorders (Meier-Ewert et al., 2004; Patel et al., 2004; Gangwisch et al., 2006, 2010; Cappuccio et al., 2007; Kerkhofs et al., 2007; Miller et al., 2009; Simpson et al., 2010; Kronholm et al., 2011; Lyytikäinen et al., 2011).

Evidence for ovarian hormone modulation of sleep and circadian rhythms in women

Clinical work demonstrates that a fluctuating ovarian hormonal milieu influences sleep throughout a woman's lifespan (Manber and Armitage, 1999; Moline et al., 2004; Dzaja et al., 2005; Baker et al., 2010). The most dramatic change in sleep across the men- 
strual cycle is increased electroencephalographic (EEG) activity in the frequency range of sleep spindles $(12-16 \mathrm{~Hz})$ in non-REMS in the postovulatory luteal phase of the menstrual cycle, when progesterone and estradiol are high, compared with the follicular phase, when progesterone is low (Driver et al., 1996; Baker et al., 2007). The increased spindle frequency activity is hypothesized to represent an interaction between endogenous progesterone metabolites and $\mathrm{GABA}_{\mathrm{A}}$ membrane receptors (Driver et al., 1996). Slow-wave sleep and activity remain stable across the menstrual cycle, indicating that sleep homeostasis is unaffected by the hormonal fluctuations in reproductively capable women. However, REMS is slightly reduced and REMS episodes are shorter in the luteal phase (Driver et al., 2008). Higher progesterone and estradiol levels correlate with less REMS (F. C. Baker, unpublished data), a finding consistent with observations in the gonadally intact female rats (Schwierin et al., 1998; Hadjimarkou et al., 2008), although rats show a corresponding increase in wakefulness not seen in humans.

While sex differences in the circadian rhythms of melatonin and body temperature have been reported (Cain et al., 2010; Duffy et al., 2011), the neurobiological mechanism underlying this sex difference in circadian alignment is not well understood. Fluctuations in gonadal hormones may not be a contributing factor as the circadian phase of melatonin and body temperature rhythms are unchanged by the hormonal fluctuations of the menstrual cycle (Shechter and Boivin, 2010). However, circadian amplitude of body temperature is blunted in the luteal phase, which may reflect actions of progesterone on the SCN or on thermosensitive neurons in the preoptic area of the hypothalamus (Shechter and Boivin, 2010), or inhibition of the nocturnal hypothermic action of melatonin (Cagnacci et al., 1996).

Perimenopause is marked by dramatic hormonal changes, including an increase in follicle-stimulating hormone (FSH) and a decline in estrogens. There is correlational evidence of a relationship between these hormonal events and sleep, with decreasing estradiol and increasing FSH levels being associated with poorer sleep quality, and a faster rate of change in FSH levels being associated with longer sleep and more non-REMS (Joffe et al., 2010a). Complaints about sleep quality are one of the most common symptoms of the menopause transition, being reported by $33-51 \%$ of women, and there is a steep increase in the prevalence of insomnia (Polo-Kantola, 2008). Again, objective PSG studies do not reflect this worsening of sleep quality and in fact have shown either no difference (Shaver et al., 1988) or, if anything, better sleep after menopause (Sharkey et al., 2003; Young et al., 2003). The extent to which sleep is disturbed during menopause may depend on the severity of menopausal symptoms. Women with significant menopausal symptoms have vastly different subjective perceptions about their sleep compared to women with few symptoms (F. C. Baker, unpublished data). Objective PSG profiles are similar between the two groups, but women with severe menopausal symptoms have less SWA than women with few symptoms, which may impact subjective sleep quality. Possibly, altered stress reactivity in symptomatic women could also affect their perceived sleep quality by modulating sympathovagal balance during sleep.

The changing hormonal environment during menopause may also influence circadian rhythms and consequently, sleep (Polo-Kantola, 2008). Postmenopausal women ( $55 \pm 2$ years) have an advanced melatonin onset compared to premenopausal women ( $42 \pm 4$ years), a difference attributed to menopause, although an effect of age could not be entirely excluded (Walters et al., 2005). An advanced circadian phase may contribute to early morning awakening, a common complaint in menopausal women (Polo-Kantola, 2011).

\section{Sleep and circadian rhythms following hormone therapy in} menopausal women

Given the evidence of a link between declining estrogens and increasing sleep problems in menopausal women, it is plausible that hormone therapy (HT) should restore sleep quality. Several studies have shown that estrogen therapy alone or combined with a progestin is associated with improved subjective sleep quality in perimenopausal and postmenopausal women (for review, see Polo-Kantola, 2011). Improved sleep may be partially due to the associated decline in vasomotor symptoms, although even women without vasomotor symptoms report improvements in sleep, suggesting that $\mathrm{HT}$ also acts via other pathways (for review, see Polo-Kantola, 2011). Despite the subjective improvements in sleep, PSG studies of the effects of HT have not shown consistent improvements in sleep architecture, with some showing decreased wake time or arousals and increased REM sleep, while others show increased awakenings or no changes in sleep (for review, see Polo-Kantola, 2011). These inconsistent findings in objective sleep measures may relate to differences between studies in HT formulations, duration of treatment, and timing of treatment in relation to menopause onset. For example, different synthetic progestins contained in HT have differences in biological activity (Africander et al., 2011) and may exert different effects on sleep (Montplaisir et al., 2001). Progestins also differ from natural progesterone and therefore can exert effects on sleep that differ from the cyclical changes that characterize the natural menstrual cycle (Baker et al., 2001). Clearer effects of HT on sleep architecture may be revealed under challenge conditions. Women taking natural progesterone or estrogen therapy show less sleep disturbance from an intravenous catheter compared to placebo or women not taking estrogen, respectively (Prinz et al., 2001; Caufriez et al., 2011). This effect might explain the subjective improvement in sleep with HT: women may be less likely to be disturbed by stressors in their environment when taking HT.

HT improves quality of life by treating menopausal symptoms, but its benefit is offset by an increased long-term risk of cancer and coronary heart disease (Taylor and Manson, 2011). Thus, HT is recommended for a limited duration. Recently, investigators have begun to study the benefits of nonhormonal treatments of menopausal insomnia. Treatment with a hypnotic was shown to improve sleep, reduce hot flashes, and improve mood in women with vasomotor symptoms (Joffe et al., 2010b).

\section{What animal models can tell us about gonadal influences and sex differences in sleep and circadian rhythms}

While both sex differences and reproductive hormones affect sleep and circadian rhythms, our understanding of the mechanisms and timing of these effects is in its infancy. Animal models, including those of hormonal changes around puberty and menopause, provide a useful approach to study these phenomena and their underlying mechanisms by allowing better-controlled experiments and more invasive approaches than are possible in humans.

Ovarian hormones modulate sleep-wake patterns in rodents Early rodent studies using EEG to record sleep generally reported that acute exogenous administration of estradiol to female rodents decreased total sleep time, but discrepancies existed as to its specific influence on REMS and non-REMS (Malven and Sawyer, 1966; Colvin et al., 1969; Branchey et al., 1971; Yamaoka, 1980). More recently, ovariectomized rats with subcutaneous ovarian 
hormone implants that stabilize steroid levels for an extended duration ( $\sim 2$ weeks) have been used to study hormonal modulation of sleep and sleep homeostasis (Deurveilher et al., 2009, 2011). The stable hormonal levels of these animals allow baseline sleep ( $24 \mathrm{~h})$, sleep deprivation $(6 \mathrm{~h})$, and recovery sleep (18-24 h) to be studied against a controlled hormonal background, which is more challenging in gonadally intact female rats undergoing rapid hormonal changes associated with estrous cycles, or after acute exogenous administration.

Studies using this approach show that physiological levels of ovarian hormones modulate sleep architecture differently at baseline and during recovery after sleep loss (Deurveilher et al., 2009 , 2011). Estradiol alone or in combination with progesterone increases wake and decreases spontaneous non-REMS and REMS. Moreover, the combination of estradiol and progesterone is synergistic, and their effects on spontaneous or baseline sleep are dramatically dependent on time of day, having the most significant effect during the dark phase in most rodent species. Thus, estradiol either alone or combined with progesterone promotes arousal in the animal's active (dark) phase by consolidating wake and fragmenting sleep (shorter non-REMS episodes, fewer REMS episodes, and more frequent brief awakenings) (Deurveilher et al., 2011), consistent with the reduced sleep of intact animals on the night of proestrus (Schwierin et al., 1998; Hadjimarkou et al., 2008).

A different picture emerges after acute sleep deprivation by gentle handing for $6 \mathrm{~h}$ during the second half of the light phase (Deurveilher et al., 2009, 2011). As expected, all animals show an increase (rebound) in non-REMS and REMS compared to baseline. Unlike at baseline, however, rats receiving a high dose of estradiol or a lower dose of estradiol in combination with progesterone achieve similar absolute levels of non-REMS and REMS amounts as vehicle-treated rats during recovery. Thus, when compared to the baseline where estradiol reduces sleep during the dark phase, estradiol-treated animals show greater consolidation of non-REMS (longer non-REMS episodes and fewer brief awakenings) during recovery. Possibly as a result of non-REMS consolidation, individual REMS episodes last longer in estradioltreated rats, leading to greater REMS rebound relative to baseline. However, sleep intensity, as assessed by non-REMS EEG delta power, still increases for a shorter period of time than in vehicletreated rats. The relatively greater consolidation of non-REMS and REMS rebound from baseline in estradiol-treated female rats is unlikely to be due to accumulation of greater sleep pressure during sleep deprivation, because ovarian hormones had no effect on the number of interventions required to keep the rats awake during the deprivation period.

\section{Age, sleep, and ovarian hormones}

In general, work in aged male rodents demonstrates a significant decrease in sleep quality as characterized by increases in sleep fragmentations and decreased SWA. In the published literature, similar studies in aged female rodents are nonexistent. Since young female rats are used in most, if not all, studies investigating the role of ovarian hormones in the modulation of sleep, it is not clear that they represent the best model to assess the controversial role of HT in improving sleep quality in perimenopausal women (Hachul et al., 2008; Kalleinen et al., 2008). To address this question, middle-aged female rats (10-12 months) were treated with ovarian hormone implants for a 2 week period. The results with these middle-aged rats are largely similar to those observed in young females, with minor differences that may be related to age-related changes in sleep regulation (M. E. Seary, S. Deurveil- her, and K. Semba, unpublished data). The promotion of spontaneous waking during the dark phase in nocturnal animals may be equivalent to increased vigilance during the day in women. This could lead to consolidation of sleep at night, which is consistent with the improved quality of sleep with hormone replacement therapy as reported in some studies (see above).

\section{Estradiol's effects on sleep: temporal versus homeostatic}

Recent work has begun to compare and contrast the effects of hormones on circadian versus homeostatic sleep regulatory mechanisms (Schwartz and Mong, 2011). It is generally accepted that sleep, in part, is a homeostatically regulated behavior where sleep pressure proportionally increases with the time spent out of sleep (Borbély and Achermann, 1999). Previous findings that estradiol-mediated suppression of REMS across the $24 \mathrm{~h}$ period did not result in a sleep rebound (Hadjimarkou et al., 2008) suggested that estradiol reduces the homeostatic drive for REMS. Since sleep deprivation typically results in a progressive accumulation of sleep need, it is a powerful tool for directly observing how an experimental manipulation influences homeostatic sleep drive. Thus, to test the prediction that estradiol attenuates the need for REMS, a total sleep deprivation (TSD) paradigm was used throughout the light phase in adult ovariectomized rats treated with oil or estradiol via capsule implants (Schwartz and Mong, 2011). Estradiol suppressed spontaneous REMS in the dark phase before and after TSD, and attenuated REM rebound during the recovery. These results suggest that estradiol alters the dynamics of REMS recovery by suppressing the homeostatic drive for REMS in the active phase. Curiously, these finding are in contrast to those reported by Deurveilher et al. $(2009,2011)$, who show that estradiol mediates an increase in REMS following sleep deprivation (Deurveilher et al., 2009). A possible explanation for these differences may be the influence of the circadian phase.

Homeostatic sleep response is modulated by circadian phase where sleep propensity is decreased during a rat's active phase (Borbély and Achermann, 1999). Thus, an alternative interpretation to estradiol suppressing recovery sleep is that estradiol is enhancing the circadian influence to suppress REMS in the dark phase. That is, estradiol consolidates the daily sleep-wake rhythms. If this were the case, estradiol would be expected to improve sleep during the day while reducing it at night. This prediction was recently tested in ovariectomized female rats treated with estradiol or control vehicle by sleep-depriving them for $6 \mathrm{~h}$ at different times during the light period to allow for recovery sleep either in the light or dark phase (M. D. Schwartz and J. A. Mong, unpublished data). At baseline, estradiol decreased REMS and non-REMS at night, consistent with previous studies (Colvin et al., 1969; Branchey et al., 1971; Evans et al., 1971; Yamaoka, 1980; Schwierin et al., 1998; Hadjimarkou et al., 2008; Deurveilher et al., 2009; Schwartz and Mong, 2011). Sleep deprivation at either time of day increased REMS time over baseline values for both estradiol- and oil-treated rats. However, estradiol treatment resulted in a larger increase in REMS during the daytime, and like the aforementioned $12 \mathrm{~h}$ TSD, attenuated recovery at night, compared to oil. Estradiol had a similar time-ofday-dependent effect on non-REM delta power. Together, these results suggest that estradiol improves circadian rhythms in sleep and waking by facilitating sleep at certain times of day while suppressing it at others. This pattern remains faithful to the $24 \mathrm{~h}$ clock, even after deprivation increases the need for sleep. Moreover, these data implicate a role of the circadian system and possibly the SCN in modulating estradiol's effects on sleep and arousal. 
Potential mechanisms underlying ovarian hormone modulation of sleep

Mechanisms by which ovarian hormones modulate sleep and sleep homeostasis are, at present, not well understood. Estrogen and progesterone receptors are localized in many sleep/wakeregulatory nuclei, including the basal forebrain, hypothalamus, dorsal raphe nucleus, and locus ceruleus (Shughrue et al., 1997; Curran-Rauhut and Petersen, 2002), and estradiol modulates sleep deprivation-induced neuronal activation as measured by FOS protein expression in these areas (Peterfi et al., 2004; Deurveilher et al., 2008).

Mounting evidence suggests that sleep nuclei in the preoptic area, which is one of only a few brain regions with overlapping expression of the estrogen receptor (ER) isoforms, $\mathrm{ER} \alpha$ and $\mathrm{ER} \beta$ (Shughrue et al., 1997; Shughrue and Merchenthaler, 2001), are potential sites for estradiol action. In particular, the ventrolateral preoptic area (VLPO) is a sleep active nucleus strongly implicated in the induction and maintenance of sleep (for review, see Saper et al., 2010). Under spontaneous sleep, estradiol inhibits activation of the sleep-promoting VLPO neurons (Hadjimarkou et al., 2008). Subarachnoid infusion of the somnogens adenosine or prostaglandin $\mathrm{D}_{2}$ promotes sleep and activates VLPO neurons (for review, see Huang et al., 2011). In the VLPO, estradiol decreases expression of lipocalin-type prostaglandin D2 synthase (Mong et al., 2003a,b; Hadjimarkou et al., 2008) and adenosine A2A receptor mRNA (Ribeiro et al., 2009), suggesting that a reduction in these signaling systems would suppress sleep and increase arousal (Mong et al., 2003a). More recently, in vitro luciferase reporter assays demonstrate that $\operatorname{ER} \alpha$ and $\operatorname{ER} \beta$ are necessary for L-PGDS promoter suppression (Devidze et al., 2010).

Finally, the SCN of mammals, including humans (Kruijver and Swaab, 2002), contains gonadal steroid receptors for estrogens, androgens, and progesterone (for review, see Karatsoreos and Silver, 2007). Thus, gonadal hormones may affect circadian rhythm and subsequently sleep via direct modulation of SCN functions. However, estradiol appears to exert its effects on circadian rhythms via extra-SCN sites projecting to the SCN (see below).

\section{The SCN and gonadal hormones}

The effects of gonadal hormones on circadian rhythmicity are clearly established; however, what is lacking is a clear understanding of how the SCN integrates these hormonal influences. The $\mathrm{SCN}$ has sparse estrogen receptor mRNA or protein. As a result, the role of steroids in females has focused primarily on extra-SCN sites of action that are estrogen receptor-rich and project to the SCN (for review, see Kriegsfeld and Silver, 2006; Karatsoreos and Silver, 2007).

In contrast, androgen receptors are prevalent in the SCN and androgenic effects are important to the circadian timing system (Karatsoreos and Silver, 2007; Iwahana et al., 2008; Karatsoreos et al., 2011). In male mice and hamsters, gonadectomy lengthens free-running period, decreases precision of daily onset of running, and eliminates early-evening but not late-night activity bouts, and testosterone replacement restores these responses (Daan et al., 1975; Morin and Cummings, 1981). As testosterone is widely aromatized to estradiol in the brain, the prevailing assumption has been that estrogenic influences predominately modulate changes in the circadian system of male rodents. However, mounting evidence demonstrates that androgens act directly in the SCN to modulate circadian rhythms in mice (Karatsoreos and Silver, 2007; Karatsoreos et al., 2011).
In the mouse, androgen receptors are localized to almost all of the gastrin-releasing peptide (GRP) cells residing in the core SCN (Karatsoreos and Silver, 2007). Functionally, the GRP cells are directly retinorecipient, responding to photic signals from retinal inputs, and thus play a significant role in synchronizing the phase of individual oscillators. Consistent with this function in the mouse, light-induced expression of Per1 mRNA and FOS protein are localized to the SCN subregion containing the GRP cells. Double-label immunohistochemistry reveals that most GRP cells contain FOS after a brief light pulse (Karatsoreos et al., 2004). Salient to androgen actions in the SCN, androgen receptor-positive cells express light-induced FOS that is attenuated by gonadectomy but restored by the nonaromatizable androgen dihydrotestosterone (Karatsoreos and Silver, 2007). Thus, since both photic input from the environment and internal signals from the body (androgens) reach the same population of cells within the SCN, these findings suggest that peripheral androgens alter SCN responses to light that in turn may affect the SCN output (Karatsoreos and Silver, 2007). Indeed, it is well established that rhythmic testosterone secretion is regulated by the SCN (Turek et al., 1984; Kriegsfeld and Silver, 2006). Together with these results, testosterone acting directly in the SCN via its cognate receptor to change the functioning of the master circadian clock supports the notion of a neuroendocrine feedback loop in the circadian system (Karatsoreos and Silver, 2007).

Androgens appear to act by altering responses to light, including induction of clock genes and behavioral phase shifting (Karatsoreos et al., 2011). Following gonadectomy, glial fibrillary acidic protein (GFAP) increases with concomitant decreases in the expression of the synaptic proteins synaptophysin and postsynaptic density 95 (PSD 95). Gonadectomy also increases lightinduced mPer1 expression in late night compared with intact controls, whereas in early night, light-induced mPer2 is decreased. Treatment of gonadectomized animals with dihydrotestosterone restored GFAP, PSD 95, and synaptophysin in the SCN and reinstated the intact pattern of molecular and behavioral responses to light. Thus, androgens modulate the state of circuitry in the mouse SCN, with functional consequences for clock gene expression and behavioral responses to photic phase-resetting stimuli.

In dose-response studies, testosterone has graded effects on the precision of activity onset, distribution, duration, and amount of daily locomotor activity, independent of the photic environment, again indicating an effect on intrinsic SCN function (M. P. Butler and R. Silver, unpublished data). Furthermore, the free-running period of locomotor activity lengthens after gonadectomy in constant dim light but not in constant darkness, suggesting that androgens can alter the processing of photic cues by the SCN. Finally, the Aschoff effect (i.e., the effect of light intensity on activity rhythms) is potentiated by gonadectomy, indicating an additive interaction between endocrine and photic cues on the circadian system.

Gonadal steroids in the SCN seem to act through different mechanisms in males and females (Fig. 2). Estradiol modulates the light-induced FOS response of serotonergic neurons of the dorsal raphe nucleus, apparently affecting the SCN through a projection via the median raphe (Abizaid et al., 2005), suggesting that estrogenic effects on circadian rhythms involve actions on SCN afferents. Thus, the sexually differentiated mechanisms of gonadal steroid action in the SCN may be a consequence of the sexually dimorphic nature of the nucleus itself. From postnatal day 21 through adulthood, male mice have significantly more androgen receptor expression in the SCN than females (Karat- 
soreos and Silver, 2007). While the mechanism for this sex difference remains relatively unknown, it appears to be independent of gonadal-hormone regulation as plasma testosterone is absent at the time of increased androgen receptor expression. One likely explanation is that patterns may be set during the prenatal or perinatal period of brain sexual differentiation.

Organizational versus activational effects of gonadal steroids on sleep and circadian rhythms

Phoenix et al. (1959) first presented evidence that a transient prenatal or early postnatal exposure to gonadal steroids permanently organizes the developing neural substrate into masculinized patterns, while the absence of steroidal exposure in the female results in feminized neural pattern. In adulthood, testicular and ovarian hormones act on the sexually differentiated circuits to activate sexspecific physiology and behavior (Phoenix et al., 1959; Arnold, 2009).

Sex differences in sleep and circadian rhythms appear in part to be modulated by exposure to steroid hormones during the perinatal period, although the mechanisms by which this occurs are still relatively unknown. Several early studies in rodents demonstrated that daily injections of ovarian hormones to male rats castrated in adulthood or female rats masculinized by testosterone exposure during development have no effect on sleep-wake patterns (Branchey et al., 1973; Yamaoka, 1980). Although the mechanisms remain unknown, these studies suggest that the ability of gonadal hormones to alter sleep is dependent on phenotypic sex.

Conversely, the evidence for the perinatal organizing effects of gonadal hormones on the circadian timing system is more extensive than that for sleep (Albers, 1981). In rodents, masculinization of the brain neonatally prevents estradiol from shortening the free-running period in adults (Zucker et al., 1980; Albers, 1981). In contrast, male hamsters castrated on the day of birth maintain this sensitivity to estrogens and exhibit a shortened tau when treated with estradiol as adults (Zucker et al., 1980). Male hamsters are better able to entrain to a long photoperiod $(24.75$ h) than are females, a sex difference which persists following castration in adulthood (Davis et al., 1983). These developmental effects of testosterone may be due, in part, to an estrogenic effect, as testosterone is aromatized to estradiol. In support of this hypothesis, female hamsters ovariectomized at birth are better able to entrain to a long photoperiod when compared to females that are ovariectomized as adults (Davis et al., 1983).

Transgenic aromatase knock-out (ArKO) mice have been used to address the activational and organizational roles of estradiol on circadian rhythm expression (Brockman et al., 2011). These mice are devoid of estradiol as they lack a functional cyp19 gene, and thus, the enzyme aromatase cytochrome P450, which converts testosterone to estradiol (Honda et al., 1998). ArKO females have the same duration of sleep as their wild-type (WT) siblings, but their sleep is more fragmented and more sleep bouts occur during their dark or active phase (Vyazovskiy et al., 2006). In contrast, recent work on the circadian system in ArKO animals reveals a complicated story of both activational and organizational effects of steroid hormones on the expression of biological rhythms (Brockman et al., 2011).

Comparisons of circadian parameters between intact and gonadectomized animals reveal that the ArKO phenotype alters responsiveness to circulating steroid hormones (Brockman et al., 2011). Gonadectomized and intact male ArKO animals do not differ with respect to their free-running period, time of activity onset, and their overall levels of activity. In contrast, castration of WT males results in a lengthened period, a delay in their activity onset, and a decrease in their activity levels. Similar to male ArKOs, and what has been reported previously, ovariectomy of intact WT females results in a decrease in activity levels. Yet surprisingly, ovariectomized female ArKO actually have increased activity compared to intact counterparts.

Comparisons of gonadectomized ArKO to WT animals reveal the organizational role of estradiol in the development of biolog- 
ical rhythms (Brockman et al., 2011). Ovariectomized WT females are more active than intact or gonadectomized ArKO females, indicating a developmental effect of estradiol on activity levels independent from that of circulating steroids. This effect is not observed in males. The time of activity onset in ovariectomized ArKO females is significantly delayed compared to intact ArKO females and ovariectomized WT females, despite all three groups being estrogen deficient. Female ArKOs, whether intact or ovariectomized, have a longer free running period than WT females.

To further test the role of estradiol in the expression of biological rhythms, WT and ArKO male and female mice were housed in constant darkness and given light pulses at different times of day (Brockman et al., 2011). Their behavioral phase shifts to the light pulses were measured; typically, animals given a pulse of light during the early portion of the night respond by having a relatively large delay in the time they become active on the following day. In WT animals, castration of males and females caused a $4 \mathrm{~h}$ shift in the peak of this behavioral response. In contrast, gonadectomized and intact ArKO animals did not differ in the time of their maximal delay in response to a light pulse. In rodents, a light pulse administered during the later portion of the night causes an advancement of activity onset. Wild-type males, regardless of whether they are intact or castrated, have phase advances that are almost twice as large as the shifts measured in ArKO animals.

Together, these data from ArKO animals provide evidence that estradiol plays a role in the modification of circadian rhythms during development in both males and females, possibly by modifying the ability of the circadian system to respond to photic cues. To determine the mechanism by which gonadal steroid hormones permanently modulate sleep and circadian rhythms we have begun to examine $\operatorname{ER} \alpha$ knock-out mice (ERKO). Male $\mathrm{ER} \alpha$ knock-out mice have an increase in daytime activity and a delayed activity onset compared to wild-type counterparts. Female wild-type mice have a larger behavioral phase shift in response to a light pulse than $\mathrm{ER} \alpha$ knock-out females. Yet in the absence of photic cues, ER $\alpha$ and WT animals do not differ with respect to their free running period in constant darkness (M. Mahoney and M. Blattner, unpublished data). By examining these parameters in gonadectomized ERKOs, we will gain insight into the organizational and activational roles of estradiol. Additionally, it will be intriguing to determine whether the distribution of steroid hormone receptors within the SCN differs in ArKO compared to WT animals, as has been shown previously in other mouse models (Karatsoreos and Silver, 2007).

Beyond gonadal hormones: influence of chromosomal complement As mentioned above, men and women sleep differently, but is this due to hormonal modulations of the sleep-wake regulatory mechanisms or are there inherent sex differences? Recent work in mice suggests that both hormone-dependent and -independent components underlie sex differences in sleep (Paul et al., 2006, 2009a,b). Sex differences in sleep-wake amount, distribution, and intensity are dependent upon the presence of gonads (Paul et al., 2006). Female mice exhibit $1.5 \mathrm{~h} / \mathrm{d}$ more wakefulness, more consolidated sleep-wake patterns with fewer arousals from sleep during their quiescent phase, and more sustained bouts of wakefulness during their normal active period than male mice. This increase in time spent awake is at the expense of non-REMS. Gonadectomy of male and female mice eliminates the sex differences in wake and non-REMS. Comparison of gonadectomized mice to intact mice of the same sex reveals that sex differences in

\section{Four Core Genotypes}

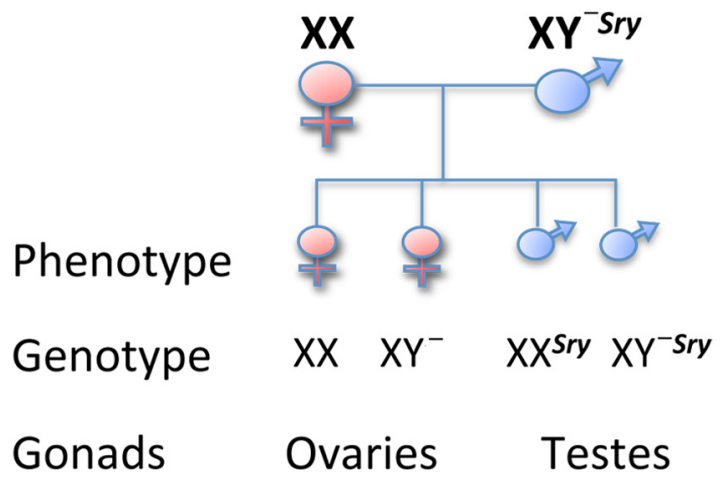

\section{Abbreviation XXF XYF XXM XYM}

\section{$2 \times 2$ Comparisons}

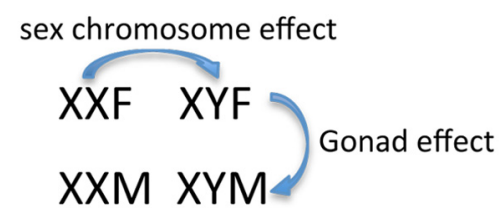

Figure 3. Schematic of four core genotype mouse model. This mouse line was initiated by a spontaneous deletion of the testis-determining gene "Sry" from the Y chromosome and the subsequent insertion of the Sry transgene onto an autosome (Mahadevaiah et al., 1998). In the absence of the Sry gene, testis development fails to occur. Thus, $X Y^{-}$mice develop ovaries and are phenotypically female. When $X Y^{-}$mice have an Sry autosomal transgene $\left(X Y^{-S r y}\right)$, they develop normal-functioning testes. The four genotypes are derived by from the crossing of $X Y^{-S r y}$ fathers and $X X$ (wild-type) mothers: $X X$ (genetic and phenotypic female), $X Y^{-}$(genetic male, phenotypic female), $X X^{\text {Sry }}$ (phenotypic male, genetic female) and $X Y^{- \text {Sry }}$ (genetic and phenotypic male). This allows a $2 \times 2$ comparison of genes versus hormones. Differences seen in mice with the same environmental milieu (such as $X X$ and $X Y^{-}$) may be attributed to possible chromosomal effects. Redrawn from Arnold and Chen (2009).

sleep-wake amounts are likely driven by ovarian hormone modulation of sleep-wake duration in females since ovariectomy decreases wake and increases non-REMS and castration had no significant affect on sleep-wake amounts. Moreover, estradiol replacement restores (i.e., suppresses) non-REMS amount in ovariectomized mice to levels observed in intact mice (Paul et al., 2009a). Curiously, testosterone replacement in males increases spontaneous non-REMS amount and enhances non-REM recovery from sleep restriction but no has effect on REM sleep (Paul et al., 2009a).

Additionally, homeostatic responses are sexually differentiated (Paul et al., 2006, 2009b). Following 6 h of sleep deprivation during the last part of the light phase, the relative increase of recovery non-REMS over baseline levels is greater in females than in males, even though recovery non-REMS or REMS amounts are not different. Consequently, females exhibit more proportional non-REMS because they have less sleep during baseline recording than males. Most interestingly, mice display sex differences in SWA during recovery from sleep deprivation. During the first $2 \mathrm{~h}$ of the recovery period, males exhibit higher normalized SWA than females. As sleep drive dissipates during the recovery period, SWA in males decreases more rapidly than in females. However, females end the recovery period with higher values than males. Similar sex differences in responses of SWA to sleep restriction 
have been reported in humans (Armitage et al., 2001) as discussed above.

A surprising finding that arose from these hormone replacement studies is that several sex differences in sleep patterns are not dependent on circulating gonadal hormones (Paul et al., 2009a). During the early dark phase, ovariectomized female mice had more NREM sleep than castrated males. There were also sex differences in more discrete ranges of EEG spectral power that were not eliminated by gonadectomy. Specifically, in the low end of non-REM delta frequencies $(.5-2 \mathrm{~Hz})$, spectral power was greater in ovariectomized females than castrated males during spontaneous sleep. These basic sex differences could result from the organizational effects of gonadal steroids (discussed above). Alternatively, genetic sex, that is, a difference in chromosome complement (XY or XX), may contribute to the sex differences.

An exciting model, the four core genotypes (FCG; Fig. 3), in which the sex chromosome complement is the opposite of gonadal sex, now enables studies that directly examine the impact of genetic sex on the sleep-wake cycle (for review, see Arnold, 2004). Studies to unmask the effects of genetic sex and phenotypic sex interactions on sleep-wake regulation in this mouse model are ongoing and suggest that chromosomal complement influences sleep (K. Paul, unpublished data). In fact, the FCG mouse model has been successful in determining the contribution of sex chromosomes and gonadal hormones to behavioral and neuroanatomical phenotypes and behavior phenotypes (Carruth et al., 2002; De Vries et al., 2002; McPhie-Lalmansingh et al., 2008; Barker et al., 2010) (see also for review Arnold and Chen, 2009). Sex differences in aggressive behavior (Gatewood et al., 2006) and autoantigen-specific immune responses (Palaszynski et al., 2005) are two salient examples where chromosomal sex acts independently of the gonads as both have influences on the sleep-wake cycle.

\section{Future directions}

The importance of sex and gonadal steroids in influencing sleep and circadian rhythms is gaining recognition with the increasing awareness of sleep disparities among men and women. As discussed, in subjective sleep studies, women report significantly more sleep problems than men, yet this perception of a poorer sleep quality in women is not reflected in objective PSG measures. This raises some intriguing questions. Do women's sleep needs differ from men's? If so, then are comparisons of PSG measures between men and women an accurate assessment of sleep quality? Our understanding of how gonadal steroids and sex are influencing sleep and biological rhythms is advancing through basic and clinical investigation. Nevertheless, more work is needed to further our understanding about the cellular and molecular mechanisms through which gonadal steroids and genetic sex are working as well as a comparison of these mechanisms in both sexes. With these advances, therapeutic targets may be elucidated that will help to alleviate the sleep pathologies associated with neuroendocrine dysfunctions.

\section{References}

Abizaid A, Mezei G, Thanarajasingam G, Horvath TL (2005) Estrogen enhances light-induced activation of dorsal raphe serotonergic neurons. Eur J Neurosci 21:1536-1546.

Africander D, Verhoog N, Hapgood JP (2011) Molecular mechanisms of steroid receptor-mediated actions by synthetic progestins used in HRT and contraception. Steroids 76:636-652.

Albers HE (1981) Gonadal hormones organize and modulate the circadian system of the rat. Am J Physiol 241:R62-R66.
Albers HE, Gerall AA, Axelson JF (1981) Effect of reproductive state on circadian periodicity in the rat. Physiol Behav 26:21-25.

Antle MC, Silver R (2005) Orchestrating time: arrangements of the brain circadian clock. Trends Neurosci 28:145-151.

Armitage R, Smith C, Thompson S, Hoffman R (2001) Sex differences in slow wave activity in response to sleep deprivation. Sleep Res Online 4:33-41.

Arnold AP (2004) Sex chromosomes and brain gender. Nat Rev Neurosci 5:701-708.

Arnold AP (2009) The organizational-activational hypothesis as the foundation for a unified theory of sexual differentiation of all mammalian tissues. Horm Behav 55:570-578.

Arnold AP, Chen X (2009) What does the "four core genotypes" mouse model tell us about sex differences in the brain and other tissues? Front Neuroendocrinol 30:1-9.

Baker FC, Mitchell D, Driver HS (2001) Oral contraceptives alter sleep and raise body temperature in young women. Pflugers Arch 442:729-737.

Baker FC, Kahan TL, Trinder J, Colrain IM (2007) Sleep quality and the sleep electroencephalogram in women with severe premenstrual syndrome. Sleep 30:1283-1291.

Baker FC, O’Brien LM, Armitage R (2010) Sex differences and menstrualrelated changes in sleep and circadian rhythms. In: Principles and practice of sleep medicine, Ed 5 (Kryger M, Roth T, Dement WC, eds), pp 15621571. St. Louis: Elsevier Saunders.

Ballinger CB (1976) Subjective sleep disturbance at the menopause. J Psychosom Res 20:509-513.

Barker JM, Torregrossa MM, Arnold AP, Taylor JR (2010) Dissociation of genetic and hormonal influences on sex differences in alcoholism-related behaviors. J Neurosci 30:9140-9144.

Borbély AA, Achermann P (1999) Sleep homeostasis and models of sleep regulation. J Biol Rhythms 14:557-568.

Born L, Shea A, Steiner M (2002) The roots of depression in adolescent girls: is menarche the key? Curr Psychiatry Rep 4:449-460.

Branchey L, Branchey M, Nadler RD (1973) Effects of sex hormones on sleep patterns of male rats gonadectomized in adulthood and in the neonatal period. Physiol Behav 11:609-611.

Branchey M, Branchey L, Nadler RD (1971) Effects of estrogen and progesterone on sleep patterns of female rats. Physiol Behav 6:743-746.

Brockman R, Bunick D, Mahoney MM (2011) Estradiol deficiency during development modulates the expression of circadian and daily rhythms in male and female aromatase knockout mice. Horm Behav 60:439-447.

Cagnacci A, Soldani R, Laughlin GA, Yen SS (1996) Modification of circadian body temperature rhythm during the luteal menstrual phase: role of melatonin. J Appl Physiol 80:25-29.

Cahill L (2006) Why sex matters for neuroscience. Nat Rev Neurosci 7:477-484.

Cain SW, Dennison CF, Zeitzer JM, Guzik AM, Khalsa SB, Santhi N, Schoen MW, Czeisler CA, Duffy JF (2010) Sex differences in phase angle of entrainment and melatonin amplitude in humans. J Biol Rhythms 25:288-296.

Cappuccio FP, Stranges S, Kandala NB, Miller MA, Taggart FM, Kumari M, Ferrie JE, Shipley MJ, Brunner EJ, Marmot MG (2007) Gender-specific associations of short sleep duration with prevalent and incident hypertension: the Whitehall II Study. Hypertension 50:693-700.

Carruth LL, Reisert I, Arnold AP (2002) Sex chromosome genes directly affect brain sexual differentiation. Nat Neurosci 5:933-934.

Caufriez A, Leproult R, L’Hermite-Balériaux M, Kerkhofs M, Copinschi G (2011) Progesterone prevents sleep disturbances and modulates GH, TSH, and melatonin secretion in postmenopausal women. J Clin Endocrinol Metab 96:E614-623.

Chou TC, Bjorkum AA, Gaus SE, Lu J, Scammell TE, Saper CB (2002) Afferents to the ventrolateral preoptic nucleus. J Neurosci 22:977-990.

Chou TC, Scammell TE, Gooley JJ, Gaus SE, Saper CB, Lu J (2003) Critical role of dorsomedial hypothalamic nucleus in a wide range of behavioral circadian rhythms. J Neurosci 23:10691-10702.

Colvin GB, Whitmoyer DI, Lisk RD, Walter DO, Sawyer CH (1968) Changes in sleep-wakefulness in female rats during circadian and estrous cycles. Brain Res 7:173-181.

Colvin GB, Whitmoyer DI, Sawyer CH (1969) Circadian sleep-wakefulness patterns in rats after ovariectomy and treatment with estrogen. Exp Neurol 25:616-625. 
Curran-Rauhut MA, Petersen SL (2002) The distribution of progestin receptor mRNA in rat brainstem. Brain Res Gene Expr Patterns 1:151-157.

Daan S, Damassa D, Pittendrigh CS, Smith ER (1975) An effect of castration and testosterone replacement on a circadian pacemaker in mice (Mus musculus). Proc Natl Acad Sci U S A 72:3744-3747.

Davis FC, Darrow JM, Menaker M (1983) Sex differences in the circadian control of hamster wheel-running activity. Am J Physiol 244:R93-R105.

Deurveilher S, Semba K (2003) Indirect projections from the suprachiasmatic nucleus to the median preoptic nucleus in rat. Brain Res 987:100-106.

Deurveilher S, Semba K (2005) Indirect projections from the suprachiasmatic nucleus to major arousal-promoting cell groups in rat: implications for the circadian control of behavioural state. Neuroscience 130:165-183.

Deurveilher S, Burns J, Semba K (2002) Indirect projections from the suprachiasmatic nucleus to the ventrolateral preoptic nucleus: a dual tracttracing study in rat. Eur J Neurosci 16:1195-1213.

Deurveilher S, Cumyn EM, Peers T, Rusak B, Semba K (2008) Estradiol replacement enhances sleep deprivation-induced c-Fos immunoreactivity in forebrain arousal regions of ovariectomized rats. Am J Physiol Regul 295:R1328-R1340.

Deurveilher S, Rusak B, Semba K (2009) Estradiol and progesterone modulate spontaneous sleep patterns and recovery from sleep deprivation in ovariectomized rats. Sleep 32:865-877.

Deurveilher S, Rusak B, Semba K (2011) Female reproductive hormones alter sleep architecture in ovariectomized rats. Sleep 34:519-530.

Devidze N, Fujimori K, Urade Y, Pfaff DW, Mong JA (2010) Estradiol regulation of lipocalin-type prostaglandin D synthase promoter activity: evidence for direct and indirect mechanisms. Neurosci Lett 474:17-21.

De Vries GJ, Rissman EF, Simerly RB, Yang LY, Scordalakes EM, Auger CJ, Swain A, Lovell-Badge R, Burgoyne PS, Arnold AP (2002) A model system for study of sex chromosome effects on sexually dimorphic neural and behavioral traits. J Neurosci 22:9005-9014.

Driver HS, Dijk DJ, Werth E, Biedermann K, Borbély AA (1996) Sleep and the sleep electroencephalogram across the menstrual cycle in young healthy women. J Clin Endocrinol Metab 81:728-735.

Driver HS, Werth E, Dijk D-J, Borbély A (2008) The menstrual cycle effects on sleep. Sleep Med Clin 3:1-11.

Duffy JF, Cain SW, Chang AM, Phillips AJ, Munch MY, Gronfier C, Wyatt JK, Dijk DJ, Wright KP Jr, Czeisler CA (2011) Sex difference in the near-24hour intrinsic period of the human circadian timing system. Proc Natl Acad Sci U S A 108:15602-15608.

Dzaja A, Arber S, Hislop J, Kerkhofs M, Kopp C, Pollmächer T, Polo-Kantola P, Skene DJ, Stenuit P, Tobler I, Porkka-Heiskanen T (2005) Women's sleep in health and disease. J Psychiatr Res 39:55-76.

Eastman CI, Mistlberger RE, Rechtschaffen A (1984) Suprachiasmatic nuclei lesions eliminate circadian temperature and sleep rhythms in the rat. Physiol Behav 32:357-368.

Edgar DM, Dement WC, Fuller CA (1993) Effect of SCN lesions on sleep in squirrel monkeys: evidence for opponent processes in sleep-wake regulation. J Neurosci 13:1065-1079.

Evans JI, MacLean AW, Ismail AA, Love D (1971) Concentrations of plasma testosterone in normal men during sleep. Nature 229:261-262.

Fitzgerald K, Zucker I (1976) Circadian organization of the estrous cycle of the golden hamster. Proc Natl Acad Sci U S A 73:2923-2927.

Franken P, Dijk DJ (2009) Circadian clock genes and sleep homeostasis. Eur J Neurosci 29:1820-1829.

Gangwisch JE (2009) Epidemiological evidence for the links between sleep, circadian rhythms and metabolism. Obes Rev 10 [Suppl 2]:37-45.

Gangwisch JE, Heymsfield SB, Boden-Albala B, Buijs RM, Kreier F, Pickering TG, Rundle AG, Zammit GK, Malaspina D (2006) Short sleep duration as a risk factor for hypertension: analyses of the first National Health and Nutrition Examination Survey. Hypertension 47:833-839.

Gangwisch JE, Malaspina D, Babiss LA, Opler MG, Posner K, Shen S, Turner JB, Zammit GK, Ginsberg HN (2010) Short sleep duration as a risk factor for hypercholesterolemia: analyses of the National Longitudinal Study of Adolescent Health. Sleep 33:956-961.

Gatewood JD, Wills A, Shetty S, Xu J, Arnold AP, Burgoyne PS, Rissman EF (2006) Sex chromosome complement and gonadal sex influence aggressive and parental behaviors in mice. J Neurosci 26:2335-2342.

Hachul H, Bittencourt LR, Andersen ML, Haidar MA, Baracat EC, Tufik S (2008) Effects of hormone therapy with estrogen and/or progesterone on sleep pattern in postmenopausal women. Int $\mathrm{J}$ Gynaecol Obstet 103:207-212.
Hadjimarkou MM, Benham R, Schwarz JM, Holder MK, Mong JA (2008) Estradiol suppresses rapid eye movement sleep and activation of sleep-active neurons in the ventrolateral preoptic area. Eur J Neurosci 27:1780-1792.

Hartmann E (1966) Dreaming sleep (the D-state) and the menstrual cycle. J Nerv Ment Dis 143:406-416.

Honda S, Harada N, Ito S, Takagi Y, Maeda S (1998) Disruption of sexual behavior in male aromatase-deficient mice lacking exons 1 and 2 of the cyp19 gene. Biochem Biophys Res Commun 252:445-449.

Huang ZL, Urade Y, Hayaishi O (2011) The role of adenosine in the regulation of sleep. Curr Top Med Chem 11:1047-1057.

Iwahana E, Karatsoreos I, Shibata S, Silver R (2008) Gonadectomy reveals sex differences in circadian rhythms and suprachiasmatic nucleus androgen receptors in mice. Horm Behav 53:422-430.

Joffe H, Massler A, Sharkey KM (2010a) Evaluation and management of sleep disturbance during the menopause transition. Semin Reprod Med 28:404-421.

Joffe H, Petrillo L, Viguera A, Koukopoulos A, Silver-Heilman K, Farrell A, Yu G, Silver M, Cohen LS (2010b) Eszopiclone improves insomnia and depressive and anxious symptoms in perimenopausal and postmenopausal women with hot flashes: a randomized, double-blinded, placebocontrolled crossover trial. Am J Obstet Gynecol 202:171.e1-171.e11.

Johnson EO, Roth T, Schultz L, Breslau N (2006) Epidemiology of DSM-IV insomnia in adolescence: lifetime prevalence, chronicity, and an emergent gender difference. Pediatrics 117:e247-256.

Jones BE (2005) From waking to sleeping: neuronal and chemical substrates. Trends Pharmacol Sci 26:578-586.

Kalleinen N, Polo O, Himanen SL, Joutsen A, Polo-Kantola P (2008) The effect of estrogen plus progestin treatment on sleep: a randomized, placebo-controlled, double-blind trial in premenopausal and late postmenopausal women. Climacteric 11:233-243.

Karatsoreos IN, Silver R (2007) Minireview: the neuroendocrinology of the suprachiasmatic nucleus as a conductor of body time in mammals. Endocrinology 148:5640-5647.

Karatsoreos IN, Yan L, LeSauter J, Silver R (2004) Phenotype matters: identification of light-responsive cells in the mouse suprachiasmatic nucleus. J Neurosci 24:68-75.

Karatsoreos IN, Butler MP, Lesauter J, Silver R (2011) Androgens modulate structure and function of the suprachiasmatic nucleus brain clock. Endocrinology 152:1970-1978.

Kerkhofs M, Boudjeltia KZ, Stenuit P, Brohée D, Cauchie P, Vanhaeverbeek M (2007) Sleep restriction increases blood neutrophils, total cholesterol and low density lipoprotein cholesterol in postmenopausal women: a preliminary study. Maturitas 56:212-215.

Klein DC, Moore RY, Reppert SM (1991) Suprachiasmatic nucleus: the mind's clock. New York: Oxford UP.

Kohsaka A, Bass J (2007) A sense of time: how molecular clocks organize metabolism. Trends Endocrinol Metab 18:4-11.

Kriegsfeld LJ, Silver R (2006) The regulation of neuroendocrine function: timing is everything. Horm Behav 49:557-574.

Kronholm E, Laatikainen T, Peltonen M, Sippola R, Partonen T (2011) Selfreported sleep duration, all-cause mortality, cardiovascular mortality and morbidity in Finland. Sleep Med 12:215-221.

Kruijver FP, Swaab DF (2002) Sex hormone receptors are present in the human suprachiasmatic nucleus. Neuroendocrinology 75:296-305.

Kyriacou CP, Hastings MH (2010) Circadian clocks: genes, sleep, and cognition. Trends Cogn Sci 14:259-267.

Luboshitzky R, Herer P, Levi M, Shen-Orr Z, Lavie P (1999) Relationship between rapid eye movement sleep and testosterone secretion in normal men. J Androl 20:731-737.

Lyytikäinen P, Rahkonen O, Lahelma E, Lallukka T (2011) Association of sleep duration with weight and weight gain: a prospective follow-up study. J Sleep Res 20:298-302.

Mahadevaiah SK, Odorisio T, Elliott DJ, Rattigan A, Szot M, Laval SH, Washburn LL, McCarrey JR, Cattanach BM, Lovell-Badge R, Burgoyne PS (1998) Mouse homologues of the human AZF candidate gene RBM are expressed in spermatogonia and spermatids, and map to a Y chromosome deletion interval associated with a high incidence of sperm abnormalities. Hum Mol Genet 7:715-727.

Malven PV, Sawyer CH (1966) Sleeping patterns in female guinea pigs; effects of sex hormones. Exp Neurol 15:229-239.

Manber R, Armitage R (1999) Sex, steroids, and sleep: a review. Sleep 22:540-555. 
Manber R, Baker FC, Gress JL (2006) Sex differences in sleep and sleep disorders: a focus on women's sleep. Int J Sleep Disorders 1:7-15.

McCarthy MM, Arnold AP (2011) Reframing sexual differentiation of the brain. Nat Neurosci 14:677-683.

McPhie-Lalmansingh AA, Tejada LD, Weaver JL, Rissman EF (2008) Sex chromosome complement affects social interactions in mice. Horm Behav 54:565-570.

Meier-Ewert HK, Ridker PM, Rifai N, Regan MM, Price NJ, Dinges DF, Mullington JM (2004) Effect of sleep loss on C-reactive protein, an inflammatory marker of cardiovascular risk. J Am Coll Cardiol 43:678-683.

Miller MA, Kandala NB, Kivimaki M, Kumari M, Brunner EJ, Lowe GD, Marmot MG, Cappuccio FP (2009) Gender differences in the crosssectional relationships between sleep duration and markers of inflammation: Whitehall II study. Sleep 32:857-864.

Mistlberger RE (2005) Circadian regulation of sleep in mammals: role of the suprachiasmatic nucleus. Brain Res Rev 49:429-454.

Moline ML, Broch L, Zak R (2004) Sleep in women across the life cycle from adulthood through menopause. Med Clin North Am 88:705-736, ix.

Mong JA, Devidze N, Goodwillie A, Pfaff DW (2003a) Reduction of lipocalin-type prostaglandin D synthase in the preoptic area of female mice mimics estradiol effects on arousal and sex behavior. Proc Natl Acad Sci U S A 100:15206-15211.

Mong JA, Devidze N, Frail DE, O'Connor LT, Samuel M, Choleris E, Ogawa S, Pfaff DW (2003b) Estradiol differentially regulates lipocalin-type prostaglandin D synthase transcript levels in the rodent brain: evidence from high-density oligonucleotide arrays and in situ hybridization. Proc Natl Acad Sci U S A 100:318-323.

Montplaisir J, Lorrain J, Denesle R, Petit D (2001) Sleep in menopause: differential effects of two forms of hormone replacement therapy. Menopause 8:10-16.

Moore RY, Eichler VB (1972) Loss of a circadian adrenal corticosterone rhythm following suprachiasmatic lesions in the rat. Brain Res 42:201-206.

Morin LP, Cummings LA (1981) Effect of surgical or photoperiodic castration, testosterone replacement or pinealectomy on male hamster running rhythmicity. Physiol Behav 26:825-838.

Morin LP, Fitzgerald KM, Zucker I (1977) Estradiol shortens the period of hamster circadian rhythms. Science 196:305-307.

Ohayon MM (1997) Prevalence of DSM-IV diagnostic criteria of insomnia: distinguishing insomnia related to mental disorders from sleep disorders. J Psychiatr Res 31:333-346.

Palaszynski KM, Smith DL, Kamrava S, Burgoyne PS, Arnold AP, Voskuhl RR (2005) A yin-yang effect between sex chromosome complement and sex hormones on the immune response. Endocrinology 146:3280-3285.

Patel SR, Ayas NT, Malhotra MR, White DP, Schernhammer ES, Speizer FE, Stampfer MJ, Hu FB (2004) A prospective study of sleep duration and mortality risk in women. Sleep 27:440-444.

Paul KN, Dugovic C, Turek FW, Laposky AD (2006) Diurnal sex differences in the sleep-wake cycle of mice are dependent on gonadal function. Sleep 29:1211-1223.

Paul KN, Turek FW, Kryger MH (2008) Influence of sex on sleep regulatory mechanisms. J Womens Health (Larchmt) 17:1201-1208.

Paul KN, Laposky AD, Turek FW (2009a) Reproductive hormone replacement alters sleep in mice. Neurosci Lett 463:239-243.

Paul KN, Losee-Olson S, Pinckney L, Turek FW (2009b) The ability of stress to alter sleep in mice is sensitive to reproductive hormones. Brain Res 1305:74-85.

Peterfi Z, Churchill L, Hajdu I, Obal F Jr, Krueger JM, Parducz A (2004) Fos-immunoreactivity in the hypothalamus: dependency on the diurnal rhythm, sleep, gender, and estrogen. Neuroscience 124:695-707.

Phoenix CH, Goy RW, Gerall AA, Young WC (1959) Organizing action of prenatally administered testosterone propionate on the tissues mediating mating behavior in the female guinea pig. Endocrinology 65:369-382.

Polo-Kantola P (2008) Dealing with menopausal sleep disturbances. Sleep Med Clin 3:121-131.

Polo-Kantola P (2011) Sleep problems in midlife and beyond. Maturitas 68:224-232.

Prinz P, Bailey S, Moe K, Wilkinson C, Scanlan J (2001) Urinary free cortisol and sleep under baseline and stressed conditions in healthy senior women: effects of estrogen replacement therapy. J Sleep Res 10:19-26.
Ribeiro AC, Pfaff DW, Devidze N (2009) Estradiol modulates behavioral arousal and induces changes in gene expression profiles in brain regions involved in the control of vigilance. Eur J Neurosci 29:795-801.

Roenneberg T, Kuehnle T, Juda M, Kantermann T, Allebrandt K, Gordijn M, Merrow M (2007) Epidemiology of the human circadian clock. Sleep Med Rev 11:429-438.

Rosenwasser AM (2009) Functional neuroanatomy of sleep and circadian rhythms. Brain Res Rev 61:281-306.

Saper CB, Cano G, Scammell TE (2005) Homeostatic, circadian, and emotional regulation of sleep. J Comp Neurol 493:92-98.

Saper CB, Fuller PM, Pedersen NP, Lu J, Scammell TE (2010) Sleep state switching. Neuron 68:1023-1042.

Schiff I, Regestein Q, Tulchinsky D, Ryan KJ (1979) Effects of estrogens on sleep and psychological state of hypogonadal women. J Am Med Assoc 242:2405-2407.

Schwartz MD, Mong JA (2011) Estradiol suppresses recovery of REM sleep following sleep deprivation in ovariectomized female rats. Physiol Behav 104:962-971.

Schwierin B, Borbély AA, Tobler I (1998) Sleep homeostasis in the female rat during the estrous cycle. Brain Res 811:96-104.

Sharkey KM, Bearpark HM, Acebo C, Millman RP, Cavallo A, Carskadon MA (2003) Effects of menopausal status on sleep in midlife women. Behav Sleep Med 1:69-80.

Shaver J, Giblin E, Lentz M, Lee K (1988) Sleep patterns and stability in perimenopausal women. Sleep 11:556-561.

Shechter A, Boivin DB (2010) Sleep, hormones, and circadian rhythms throughout the menstrual cycle in healthy women and women with premenstrual dysphoric disorder. Int J Endocrinol 2010:259345.

Shughrue PJ, Merchenthaler I (2001) Distribution of estrogen receptor beta immunoreactivity in the rat central nervous system. J Comp Neurol 436:64-81.

Shughrue PJ, Lane MV, Merchenthaler I (1997) Comparative distribution of estrogen receptor-alpha and -beta mRNA in the rat central nervous system. J Comp Neurol 388:507-525.

Siegel JM (2011) REM sleep: a biological and psychological paradox. Sleep Med Rev 15:139-142.

Simpson NS, Banks S, Dinges DF (2010) Sleep restriction is associated with increased morning plasma leptin concentrations, especially in women. Biol Res Nurs 12:47-53.

Spiegel K, Leproult R, Van Cauter E (1999) Impact of sleep debt on metabolic and endocrine function. Lancet 354:1435-1439.

Stephan FK, Zucker I (1972) Circadian rhythms in drinking behavior and locomotor activity of rats are eliminated by hypothalamic lesions. Proc Natl Acad Sci U S A 69:1583-1586.

Szymusiak R, McGinty D (2008) Hypothalamic regulation of sleep and arousal. Ann N Y Acad Sci 1129:275-286.

Taylor HS, Manson JE (2011) Update in hormone therapy use in menopause. J Clin Endocrinol Metab 96:255-264.

Turek FW, Swann J, Earnest DJ (1984) Role of the circadian system in reproductive phenomena. Recent Prog Horm Res 40:143-183.

Vyazovskiy VV, Kopp C, Wigger E, Jones ME, Simpson ER, Tobler I (2006) Sleep and rest regulation in young and old oestrogen-deficient female mice. J Neuroendocrinol 18:567-576.

Walters JF, Hampton SM, Ferns GA, Skene DJ (2005) Effect of menopause on melatonin and alertness rhythms investigated in constant routine conditions. Chronobiol Int 22:859-872.

Williams D (1971) The menopause. Br Med J 2:208-210.

Yamaoka S (1980) Modification of circadian sleep rhythms by gonadal steroids and the neural mechanisms involved. Brain Res 185:385-398.

Young T, Rabago D, Zgierska A, Austin D, Laurel F (2003) Objective and subjective sleep quality in premenopausal, perimenopausal, and postmenopausal women in the Wisconsin Sleep Cohort Study. Sleep 26:667-672.

Zhang B, Wing YK (2006) Sex differences in insomnia: a meta-analysis. Sleep 29:85-93.

Zhang J, Li AM, Kong AP, Lai KY, Tang NL, Wing YK (2009) A communitybased study of insomnia in Hong Kong Chinese children: prevalence, risk factors and familial aggregation. Sleep Med 10:1040-1046.

Zucker I, Fitzgerald KM, Morin LP (1980) Sex differentiation of the circadian system in the golden hamster. Am J Physiol 238:R97-R101. 